\title{
Evaluation of Medication Therapy Management Services for Patients with Cardiovascular Disease in a Self-Insured Employer Health Plan
}

\author{
Saranrat Wittayanukorn, BSc, MS; Salisa C. Westrick, PhD; Richard A. Hansen, PhD \\ Nedret Billor, PhD; Kimberly Braxton-Lloyd, PharmD; Brent I. Fox, PharmD, PhD; \\ and Kimberly B. Garza, PharmD, MBA, PhD
}

\begin{abstract}
BACKGROUND: Cardiovascular disease (CVD) is a major cause of mortality in the United States, representing the highest total expenditures among major diseases. To improve CVD-associated outcomes, medication therapy management (MTM) services have been included in essential health benefit packages offered by various health plans. Nevertheless, the impact of such MTM services on outcomes is still unclear, especially from the perspective of the self-insured employer.
\end{abstract}

OBJECTIVES: To (a) compare economic outcomes between patients who received and those who did not receive MTM services from the self-insured employer's perspective and (b) compare clinical outcomes before and after receiving MTM services.

METHODS: This study consisted of 2 pre- and post-retrospective designs: (1) a cohort study with comparison groups and (2) a cohort study within group comparison. Patients were beneficiaries aged 19 years or older who were diagnosed with CVD conditions according to ICD-9-CM codes and continuously enrolled in a public university-sponsored insurance plan between 2008-2010. Patients were divided into MTM and non-MTM groups. The first MTM encounter was assigned as the index date for the MTM group. Match-paired patients who did not receive MTM services were randomly assigned the index date based on age category, gender, and comorbidity. Measures for pharmacy, medical, and total expenditures were obtained from medical and pharmacy claims. Paired t-tests and independent $t$-tests using data generated from 1000 bootstraps compared mean cost difference within and between groups. The return on investment (ROI) was calculated by dividing the average net benefit from MTM services by the average cost of MTM services. Clinical parameters, including blood pressure (BP) and body mass index (BMI), were retrieved from electronic medical records from a pharmacist-provided clinic where MTM services took place. Paired-t tests were used to compare the mean difference between baseline and endpoint values. Further, this study examined changes in the proportion of patients who achieved an individualized treatment goal for BP and BMI. The study also quantified the improvement in disease stages after the index date using the McNemar's test. Statistical analyses were performed by using SAS software version 9.2 with statistical significance level of 0.05 .

RESULTS: A total of 63 patients and 62 match-paired patients were included in the MTM group and the non-MTM group, respectively. The mean cost (SD) per patient in the MTM group during the 6 months post-index period for CVD-related pharmacy, all-cause medical, and total expenditures was lower than the 6 months pre-index period by $\$ 22.0$ (19.1), $\$ 79.2$ (99.6), and $\$ 75.1$ (136.2), respectively. In contrast, the mean cost (SD) for the nonMTM group increased during the 6 months post-index date by $\$ 10.7$ (24.2), \$246.4 (248.4), and \$289.0 (269.5) for pharmacy, medical, and total expenditure, respectively. When comparing the 2 groups, the MTM group had statistically significantly lower costs per patient for pharmacy expenditures (difference of $-31.9 \pm 25.1, P<0.0001$ ), medical expenditures (difference of $-\$ 325.6 \pm 271.2, P<0.0001$ ), and total direct expenditures (difference of $-\$ 359.3 \pm 219.2, P<0.0001)$. Given the net benefit of MTM services (\$359.3) and the average cost of MTM service (\$134.6), the R0I was \$1.67 per $\$ 1$ in MTM cost. Regarding clinical outcomes, while no statistically significant differences were observed in clinical outcomes, MTM services demonstrated clinical benefits. At the post-index period, the percentage of patients who had achieved their goals increased from $55 \%$ to $70 \%$ for BP and from $13.0 \%$ to $21.7 \%$ for normal BMI compared with the pre-index period. In terms of the extent of improvement in disease stages, clinical improvements in the stages of hypertension $\left(\chi^{2}=12.77, P<0.05\right)$ as well as BMI $\left(\chi^{2}=6.39, P<0.05\right)$ at the endpoint were observed.

CONCLUSIONS: Cardiovascular-related pharmacy, all-cause medical, and total expenditures were statistically lower among beneficiaries who received MTM services compared with those who did not. In addition, MTM services had a positive $\mathrm{ROI}$ and demonstrated clinical significances by the increasing number of patients who achieved treatment goals and improved disease stages for hypertension and BMI.

J Manag Care Pharm. 2013;19(5):385-95

Copyright $\odot$ 2013, Academy of Managed Care Pharmacy. All rights reserved.

\section{What is already known about this subject}

- Cardiovascular disease (CVD) is one of the major causes of mortality globally regardless of ethnicity and gender. It has the highest total expenditures among major leading health conditions and, when extrapolated to 2013 , will contribute $\$ 818$ billion to total direct health care costs

- Continually rising health care costs cause self-insured employers to find practical strategies to reduce health care costs while maintaining or improving health outcomes among their enrollees. This has increased the offering of medication therapy management (MTM) services as part of health benefits.

- Previous studies have reported that pharmacist-provided MTM services improved clinical, economic, and humanistic outcomes; however, few studies have evaluated MTM services from the selfinsured employer's perspective. This perspective is important because $55.8 \%$ of health insurance coverage among nonelderly in the United States is provided by self-insured employers. 


\section{Evaluation of Medication Therapy Management Services for Patients with Cardiovascular Disease in a Self-Insured Employer Health Plan}

\section{What this study adds}

- This study is important because it was based on a self-insured employer's perspective considering that self-insured employers play a vital role in the U.S. health care system.

- Cardiovascular-related pharmacy, all-cause medical, and total expenditures were statistically lower among beneficiaries who received MTM services compared with those who did not. The return on investment during a 6-month period of this MTM service was 1.67 , which may be of interest to self-insured employers.

- This study evaluated both the economic and the clinical outcomes in parallel. Therefore, this study has insight that goes beyond studies that only evaluate clinical outcomes or only evaluate economic outcomes. Through this study, MTM services demonstrated clinical significance in terms of achieving goals and improving disease stages, as well as significantly reducing pharmacy, medical, and total expenditures.

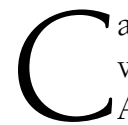
ardiovascular disease (CVD) remains a health problem within the United States. Approximately 82.6 million American adults have 1 or more types of CVD, such as hypertension, coronary heart disease, and heart failure. ${ }^{1}$ This prevalence has shown no improvement in the past decade. ${ }^{2}$ In fact, CVD continues to be 1 of the 15 leading causes of mortality globally. In 2007, it accounted for an estimated 33.6\% of all deaths in the United States. ${ }^{3}$ In terms of its economic impact, according to the Medical Expenditure Panel Survey, in 2008 CVD represented the highest total expenditures among major leading health conditions. ${ }^{4}$ These CVD conditions also accounted for the highest proportion of total hospitalization expenditures and were the primary cause of hospital stay in 2008. ${ }^{5}$ The annual expenditures of CVD in the United States are projected to exceed $\$ 1$ trillion by $2030{ }^{6}$

The increase in expenditures among patients with CVD presents a great concern to third-party payers and self-insured employers. To address this concern, third-party payers and employers are implementing interventions to reduce health care costs..$^{7-9}$ Realizing that pharmacists can be a viable solution to help improve economic and health outcomes, ${ }^{10-17}$ some health plans have started to offer pharmacist-provided care as part of their benefits packages. This pharmacist-provided care is referred to as medication therapy management (MTM) services.

Research has consistently found that having pharmacists involved in patient care improves clinical outcomes among patients with chronic disease, including CVD. ${ }^{18-27}$ Specifically, pharmacist-provided MTM services improve several cardiovascular indicators, such as decreased mean systolic and diastolic blood pressure (BP), improved lipid panel levels, and improved percentage of patients at their goals for each of these param- eters. ${ }^{10-12,28,29}$ MTM services also decrease cardiovascularrelated emergency room (ER) visits and hospitalizations that contribute to high health care expenditures, morbidity, or mortality. 10,30 In addition to clinical outcomes, MTM services can improve direct and indirect cost savings and can also have positive results on benefit-to-cost ratio and return on investment. ${ }^{10-12,31-33}$

The primary goal of this study was to evaluate the impact of pharmacist-provided MTM services from the self-insured employer perspective. This study contributes to the existing literature in 2 respects: it reflects the self-insured employer's perspective, and it evaluates both the economic and the clinical impact of MTM services. The self-insured employer's perspective was chosen because this sector provides a large portion of health insurance benefits in the United States. Specifically, about 32.3 million out of 56.1 million employees with employer-sponsored coverage in the private sector were enrolled in self-insured plans in 2010. ${ }^{34}$ In fact, the percentage of self-insured enrollees increased significantly for large firms of 50 or more employees from 2000 to 2010 (57.9\% vs $67.5 \%) .{ }^{34}$ Despite the large number of self-insured employers, few studies have investigated the impact of MTM services from the self-insured employer perspective, which warrants the need for additional studies. Further, most existing studies report the impact of MTM services in terms of percentage change in clinical outcomes (e.g., BP), which may or may not be clinically significant. Hence, building on existing studies, this study evaluates the impact of MTM services on clinical and economic outcomes. ${ }^{10,12,29,35}$

\section{Study Objectives and Hypotheses}

The primary goal of this study was to evaluate the impact of MTM services on economic and clinical outcomes among patients with CVD conducted from the self-insured employer perspective. Specific objectives were to (a) evaluate the impact of MTM services on economic outcomes among patients who received MTM services compared with those who did not receive MTM services and (b) evaluate the impact of MTM services on clinical outcomes among patients with CVD. This study hypothesized that (a) there was a difference in economic outcomes between patients with CVD who received MTM services and patients who did not receive MTM services, and (b) there was a difference in clinical outcomes among patients with CVD after receiving MTM services.

\section{Methods}

\section{Description of the Study Design}

This study was conducted from the perspective of a self-insured employer using data collected during 2008-2010. The study consisted of 2 study designs. First, a pre- and post-retrospective cohort with comparison groups was used for the economic analysis. Second, a pre- and post-retrospective cohort design 


\section{Evaluation of Medication Therapy Management Services for Patients with Cardiovascular Disease in a Self-Insured Employer Health Plan}

was used for the clinical analysis. The self-insured employer was a public university in the southeastern United States. MTM services were delivered at a pharmacist-provided pharmaceutical care center (PCC) on the university campus. The PCC provided dispensing services as well as pharmacist-provided MTM, wellness, and disease prevention services for employees, their dependents, and retirees. The study was reviewed and approved by the university's Institutional Review Board.

\section{Description of the Intervention}

The intervention in this study was pharmacist-provided MTM services for patients with CVD. The intervention group is referred to as the MTM group, hereafter. The patients in this group received MTM services from the PCC. Patients in the MTM group were identified by the pharmacists, referred from physicians, or solicited services themselves (self-selection). MTM services were provided to patients via face-to-face consultation for 30-60 minutes per encounter. The services may or may not have included follow-up visits to assess the progress of the patient on the medication management plan that was developed during the initial MTM consultation. During MTM visits, pharmacists at the PCC provided individualized MTM services for patients, including medication reviews, identification and assessment of drug-related problems (DRP), resolution and monitoring of DRPs, adherence assessment, and interventions. The pharmacists at the PCC were trained to identify, resolve, and document DRPs. DRP classifications used at the PCC were modified from the DRP classification system established by Hepler and Strand (1990) and Cipolle et al. (2004). ${ }^{36,37}$ Additionally, depending on patients' problem lists and their medication profiles, point-of-care tests including BP, lipid panels, and body mass index (BMI) may have been performed by the pharmacist. Progress notes that included subjective and objective data, an assessment, and a plan were documented in the electronic medical record (EMR).

\section{Outcome Measures}

Demographic data, including gender, age, comorbidity, and CVD conditions, were captured from the plan's claims database to describe the MTM group and also were used for a random matching of patients who did not receive MTM services. This comparison group is referred to as the non-MTM group.

Economic Outcomes. Direct costs from the self-insured employer perspective were measured including pharmacy, medical, and total (pharmacy and medical) health expenditures during 6 months pre- and post-index periods. Cost savings was calculated as the mean cost difference between 6 months preand post-index periods. Medical claims included all-cause or total medical cost of administering medical care and follow-up, cost of physicians' visits, cost of hospitalization or ER visits, cost of laboratory tests, and cost of medical procedures.
Clinical Outcomes. Clinical outcomes included lipid panels, BP, and BMI, since these are indicators of CVD risk. Specifically, this study examined (a) changes in lipid panels, BP, and BMI between baseline and the endpoint values; (b) changes in the proportion of patients who achieved the treatment goal after the index date; and (c) change in patients' disease stages. Treatment goals for lipid panels and BP were individualized for each patient and based on the Adult Treatment Panel III and the Seventh Report of the Joint National Committee on Prevention, Detection, Evaluation, and Treatment of High Blood Pressure (JNC 7) classification, respectively. ${ }^{38}$ For instance, patients with diabetes or chronic kidney disease were assigned a BP goal of $<130 / 80$ millimeters of mercury $(\mathrm{mmHg}$ ), and those without diabetes or chronic kidney disease were assigned a BP goal of $<140 / 90 \mathrm{mmHg}$. Treatment goal for BMI was defined as a BMI of 18.5-24.9 kilogram per square meter $\left(\mathrm{kg} / \mathrm{m}^{2}\right)$.

Clinical values at baseline were defined as the most recent value documented in the EMR before the index date. The value must have been measured within 6 months before the index date. This value represented the patient's most recent condition before obtaining an MTM service. As for the endpoint value, the value must have been measured within 100 days after the index date. Further, if patients had only 1 measurement after the index date, that laboratory value was used as the endpoint following a last observation carried forward approach. ${ }^{39}$ If multiple measurements were present during the 100-day interval, the last value was used.

\section{Data Sources}

Multiple sources of data were used, including medical claims, pharmacy claims, billing invoices submitted to the self-insured employer for MTM services, and EMR. First, a retrospective analysis of administrative claims was conducted using the plan's claims database. This database included enrollment data as well as medical and pharmacy claims of employees and their dependents aged 19 years or older who were continuously enrolled between January 1, 2008, through December 31, 2010. Next, billing invoices were used to determine the cost of MTM services that the employer paid the PCC. Lastly, EMR data from the MTM services were obtained from the PCC for the clinical analysis.

\section{Patient Selection}

Patients were required to have at least 1 diagnosis code for CVD conditions, including hypertension, hyperlipidemia, coronary heart disease, heart failure, stroke, and other form of heart disease (Figure 1). This information was obtained from the medical claims data, using the first 3 digits of the International Classification of Diseases, Ninth Revision, Clinical Modification (ICD-9-CM) codes. All study ICD-9-CM codes are provided in the Appendix (available online). In order to 

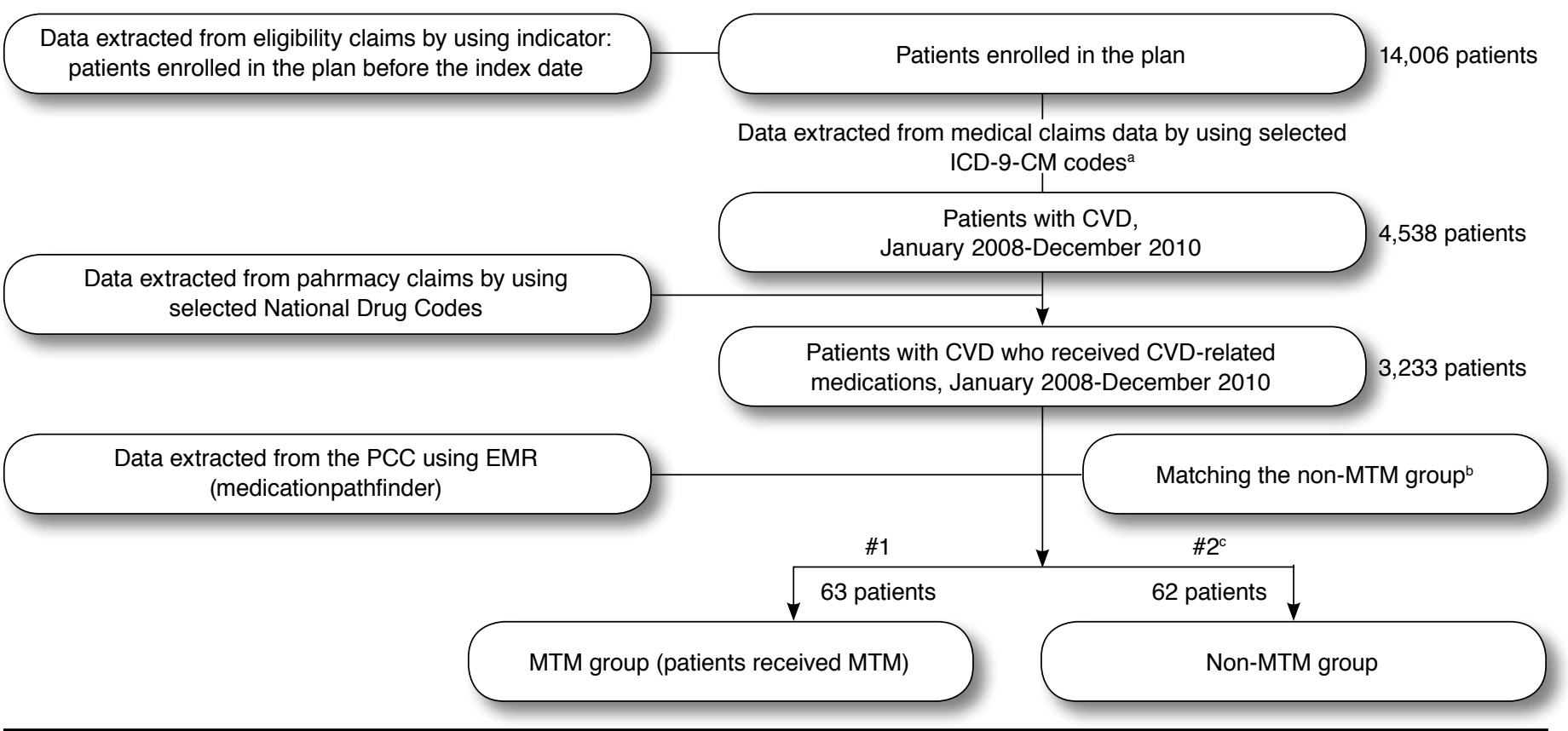

\footnotetext{
a ICD-9-CM codes for the following: Hypertension: 401, 403; CHD: 410, 411, 412, 413, 414; HF: 428; Stroke: 430-438; Hyperlipidemia: $270.0-270.4$.

$b \# 1$ and $\# 2$ were matched by using sex, age category, and Charlson Comorbidity Index score.

c\#2 was randomly assigned the index date.

$C H D=$ coronary heart disease; $C V D=$ cardiovascular disease; $E M R=$ electronic medical record; HF= heart failure; ICD-9-CM=International Classification of Diseases, Ninth Revision, Clinical Modification; MTM = medication therapy management; PCC=pharmacist-provided pharmaceutical care clinic.
}

be eligible for economic analysis, patients were required to be enrolled in the insurance plan for at least 6 months before and after the index date for a total of at least 12 months of continuous enrollment. For the MTM group, the "index date" was the date of the first MTM encounter at the PCC between January 1 , 2008, and December 31, 2010. Eligible patients must have had at least 1 pharmacy claim for a CVD-related medication during the 6 months pre-index date and at least 1 claim during the 6 months post-index period. National Drug Codes were used to identify CVD-related prescriptions. Cardiovascular-related and other relevant medical health care costs were measured using the medical claims. Further, patients included in the MTM group were selected into the clinical analysis if they had least 1 clinical measurement during the 6 months pre-index date (i.e., baseline value) and at least 1 respective measurement during the 6 months post-index date (i.e., endpoint value). A comparison group was not feasible for this analysis because clinical measures for non-MTM patients were not available. Patients younger than 19 years were excluded from the study.

The non-MTM group was defined as matched-pair patients who did not receive MTM services but were diagnosed with CVD conditions and had CVD-related medications (Figure 1).
First, patients who were retained in the economic analysis and did not receive MTM service at the PCC were randomly matched to the MTM group based on age category, gender, and comorbidity, using the Charlson Comorbidity Index (CCI). ${ }^{40}$ Since this study was not a randomized control study, using a random index date for the non-MTM group is an appropriate approach to address selection bias. The approach used in this study was similar to previous studies. ${ }^{41,42}$ Next, the "index date" for each non-MTM patient was assigned by randomly selecting the date between the patient's first enrollment date plus 6 months and the patient's last enrollment date minus 6 months between January 1, 2009, and January 31, 2011. For example, if a patient in the non-MTM group had enrolled on August 1, 2009, and the last enrollment date was December 1, 2010, then the index date for this patient was randomly selected between the period of January 1, 2010, and June 30, 2010.41,42 Similarly, individuals in the non-MTM group were required to be continuously enrolled for at least 6 months prior and after their randomly assigned index date and must have had at least 1 refill of CVD-related medication during the 6 months prior and after the assigned index date. 


\section{Evaluation of Medication Therapy Management Services for Patients with Cardiovascular Disease in a Self-Insured Employer Health Plan}

\section{Statistical Analyses}

Frequency distributions and chi-square tests were used to describe and compare patients' characteristics between MTM and non-MTM groups, respectively. Means (and standard deviations) and independent t-tests were used to describe and compare patients' ages between the 2 groups.

Next, for the economic analysis, a 1000 bootstrap replication of the original data was used. This approach is recommended for studies with small sample sizes and skewed data. ${ }^{43-47}$ Differences in mean direct costs during the 6-month pre- and post-index dates were compared within each group and between MTM and non-MTM groups using t-tests. Additionally, the study calculated a return on investment (ROI) for offering MTM services. To calculate ROI, the net benefit of MTM services was divided by the cost of MTM services. The average cost of MTM services per patient was obtained from the invoices billed to the university by the PCC.

For the clinical parameters, paired-t tests were used to compare mean differences between the baseline and endpoint values among patients who received MTM services. Due to a small sample size of lipid panels, statistical analysis for lipid panel variables (high-density lipoprotein, low-density lipoprotein, triglycerides, and cholesterol) could not be performed. To determine if there was an improvement in disease stages, a generalization of the McNemar's test (Bhapkar's test) was used. Clinical outcomes were classified into multiple categories: (a) hypertension stages: normal BP $(<120 / 80 \mathrm{mmHg})$, prehypertension (120-139/80-89 mmHg), hypertension stage 1 (140-159/99-99 $\mathrm{mmHg}$ ), hypertension stage $2(\geq 160 / \geq 100$ $\mathrm{mmHg})$; and (b) body mass index stages: underweight $(<18.5$ $\mathrm{kg} / \mathrm{m}^{2}$ ), healthy weight $\left(18.5-24.9 \mathrm{~kg} / \mathrm{m}^{2}\right)$, overweight (25.0$\left.29.9 \mathrm{~kg} / \mathrm{m}^{2}\right)$, obese $\left(\geq 30.0 \mathrm{~kg} / \mathrm{m}^{2}\right)$. McNemar's test was used to test whether the distribution of patients in the 4 hypertension stages (or BMI stages) before the index date differed from the distribution of patients after the index date. Differences were considered statistically significant when the alpha value was less than 0.05. All data extraction and analyses were performed using Statistical Analysis Software (SAS) version 9.2 (SAS Institute, Inc., Cary, NC). All comparisons were 2-sided and statistical significance was conducted at $P<0.05$.

\section{Results}

\section{Baseline Characteristics}

A total of 63 patients were included in the MTM group, and 62 match-paired patients were included in the non-MTM group (Figure 1). Baseline characteristics of patients in the MTM group and the non-MTM group are displayed in Table 1. For the matched groups, patients were similar with respect to gender, age, age category, CCI score, and CVD conditions. The majority of patients were male (61.9\% for the MTM group and $61.3 \%$ for the non-MTM group). The average age (standard deviation [SD]) was 56.8 (9.3) and 56.9 (9.6) for the MTM and the non-MTM groups, respectively. More than $60 \%$ of patients in the MTM and the non-MTM groups were between the ages of 51-65 years. In terms of comorbidity, the CCI scores were 1.0 and 0.9 for the MTM and non-MTM groups, respectively. The majority of patients were diagnosed with hypertension, and more than half of patients had hypertension with dyslipidemia (61.9\% and $51.6 \%$, respectively).

Health care utilization was similar for patients in the MTM and non-MTM groups when considering the number of CVDrelated pharmacy claims $\left(\chi^{2}=2.336 ; d f=3 ; P=0.505\right)$, number of CVD-related medications $\left(\chi^{2}=0.001 ; d f=1 ; P=0.979\right)$, and number of all-cause medical claims $\left(\chi^{2}=4.356 ; d f=4 ; P=0.359\right)$. The average number of CVD-related medications (SD) was 1.9 (0.9) in the MTM group compared with 1.8 (1.1) in the nonMTM group. When categorized by number of medications or pharmacy claims, more than $90 \%$ of patients had 1-3 CVDrelated medications. Approximately 50\% of patients in both groups did not have medical claims. Small percentages of MTM patients and non-MTM patients had greater than 10 pharmacy claims (3.2\% vs. $1.6 \%)$ and greater than 10 medical claims (7.9\% vs. 3.2\%). No patients in the MTM group had a 6-month pre-index hospitalization or ER visit, while a few patients in the non-MTM group had hospitalizations and/or ER visits.

\section{Economic Outcomes}

The mean direct cost for pharmacy, medical, and total expenditures among the MTM and the non-MTM groups are reported in Table 2. The direct cost per patient in the MTM group for all expenditure categories during the post-index period was lower than the cost during the pre-index period. For example, the mean cost of pharmacy expenditures [SD] per patient during the 6-month post-index period (\$104.8 [17.8]) decreased from the 6-month pre-index period (\$126.8 [20.3]). On the contrary, the mean cost of pharmacy, medical, and total expenditures for the non-MTM group increased after the index date. When comparing between the 2 groups, the MTM group had statistically significant improvements in mean cost per patient in a 6-month period for pharmacy expenditures (difference of $-\$ 31.9 \pm 25.1, P<0.0001$ ), medical expenditures (difference of $-\$ 325.6 \pm 271.2, P<0.0001$ ), and total direct expenditures (difference of $-\$ 359.3 \pm 219.2, P<0.0001$ ), compared with the non-MTM group.

Regarding the ROI, the average cost of MTM services per patient was calculated. The initial MTM visit was $\$ 120$, and subsequent visits were capped at $\$ 40$. Based on the PCC records, 38 patients had 1 MTM visit, and 25 had 2 or more visits. The average cost of MTM services was $\$ 134.6$ per patient. The average total direct cost difference between the 2 groups, or in other words, the average total benefit per patient, was $\$ 359.3$ in a 6 -month period. The average net benefit 


\section{Evaluation of Medication Therapy Management Services for Patients with Cardiovascular Disease in a Self-Insured Employer Health Plan}

\section{TABLE 1 Baseline Characteristics of Patients in MTM and Non-MTM Groups Enrolled}

in a Medical and Pharmacy Claims Database: 2008-2010a

\begin{tabular}{|c|c|c|c|c|c|c|c|}
\hline General Charactistics ${ }^{b}$ & MTM n (\%) & Non-MTM n (\%) & $P$ Value & General Charactistics $^{b}$ & MTM n (\%) & Non-MTM n (\%) & $P$ Value \\
\hline Number & 63 & 62 & & \multicolumn{4}{|c|}{ CVD-related pharmacy claims (continued) } \\
\hline Gender & & & $0.943(d f=1)$ & CVD-related medications $^{c}$ & & & $0.979(d f=2)$ \\
\hline Male & $39(61.9)$ & $38 \quad(61.3)$ & & $1-3$ medications & $58(92.1)$ & $57 \quad(91.9)$ & \\
\hline Female & $24(38.1)$ & $24 \quad(38.7)$ & & 4-6 medications & $5 \quad(7.9)$ & $5 \quad(8.1)$ & \\
\hline Mean [SD] age in years & $56.8 \quad[9.3]$ & $56.9 \quad[9.6]$ & 0.933 & \multirow{2}{*}{$\begin{array}{l}\text { Mean number of pharmacy } \\
\text { claims [SD] }\end{array}$} & \multirow{2}{*}{$2.9 \quad[2.1]$} & \multirow[t]{2}{*}{$2.4 \quad[2.0]$} & \\
\hline Age category & & & $0.999(d f=3)$ & & & & \\
\hline $21-35$ & $0 \quad(0)$ & $0 \quad(0)$ & & Pharmacy claims & & & $0.505(d f=3)$ \\
\hline $36-50$ & $16(25.4)$ & $15 \quad(24.2)$ & & 1-3 claims & $45(71.4)$ & $51 \quad(82.3)$ & \\
\hline $51-65$ & $39(61.9)$ & $39 \quad(62.9)$ & & 4-6 claims & $14(22.2)$ & $8 \quad(12.9)$ & \\
\hline $66-80$ & $6 \quad(9.5)$ & $6 \quad(9.7)$ & & 7-9 claims & $2(3.2)$ & $2 \quad(3.2)$ & \\
\hline $81+$ & $\begin{array}{rr}2 & (3.2) \\
1 & 0\end{array}$ & $\begin{array}{rr}2 & (3.2) \\
0 & 00\end{array}$ & & 10 claims or more & $2(3.2)$ & $1 \quad(1.6)$ & \\
\hline $\begin{array}{l}\text { Charlson Comorbidity } \\
\text { Index score, mean (range) }\end{array}$ & & & $0.986(d f=6)$ & $\begin{array}{l}\text { Total number of pharmacy } \\
\text { claims }\end{array}$ & 187 & 153 & \\
\hline$\frac{0}{1}$ & $\begin{array}{ll}29(46.0) \\
19(30.2)\end{array}$ & $\begin{array}{ll}29 & (46.8) \\
19 & (30.6)\end{array}$ & & $\begin{array}{l}\text { Total number of generic } \\
\text { medications }\end{array}$ & 111 & 80 & \\
\hline 2 & $8(12.7)$ & $8 \quad(12.9)$ & & Total number of brand & 50 & 62 & \\
\hline 3 & $4 \quad(6.3)$ & $4 \quad(6.5)$ & & medications & & & \\
\hline 4 & $1 \quad(1.6)$ & $(1.6)$ & & \multicolumn{4}{|l|}{ All-cause medical claims ${ }^{d}$} \\
\hline 5 & $1 \quad(1.6)$ & $(1.6)$ & & \multirow{2}{*}{$\begin{array}{l}\text { Mean number of medical } \\
\text { claims [SD] }\end{array}$} & \multirow{2}{*}{$\begin{array}{ll}5.2 & {[6.1]}\end{array}$} & \multirow{2}{*}{$\begin{array}{ll}4.5 & {[3.1]}\end{array}$} & \\
\hline 7 & $1 \quad(1.6)$ & $(0.0)$ & & & & & \\
\hline Cardiovascular conditions & & & $0.798(d f=5)$ & Medical claims & & & $0.359(d f=4)$ \\
\hline Congestive heart disease & $9(14.3)$ & $9 \quad(14.5)$ & & None & $32(50.8)$ & $31 \quad(50.0)$ & \\
\hline Dyslipidemia & $47(74.6)$ & $45 \quad(72.6)$ & & 1-3 claims & $16(25.4)$ & $16 \quad(25.8)$ & \\
\hline Hypertension & $55(87.3)$ & $49 \quad(79.0)$ & & 4-6 claims & $8(12.7)$ & $6 \quad(9.7)$ & \\
\hline $\begin{array}{l}\text { Hypertension with } \\
\text { dyslipidemia }\end{array}$ & 39 (61.9) & 32 (51.6) & & 7-9 claims & $2(3.12)$ & $7 \quad(11.3)$ & \\
\hline Heart failure & $2 \quad(3.2)$ & $2 \quad(3.2)$ & & 10 claims or more & $5 \quad(7.9)$ & $2 \quad(3.3)$ & \\
\hline Stroke & $(9.5)$ & $(8.0)$ & & $\begin{array}{l}\text { Total number of medical } \\
\text { claims }\end{array}$ & 161 & 138 & \\
\hline \multicolumn{4}{|c|}{ CVD-related pharmacy claims } & & & & \\
\hline \multirow{2}{*}{$\begin{array}{l}\text { Mean number of CVD- } \\
\text { related medications [SD]c }\end{array}$} & \multirow{2}{*}{$\begin{array}{ll}1.9 & {[0.9]}\end{array}$} & \multirow[t]{2}{*}{$\begin{array}{ll}1.7 & {[1.1]}\end{array}$} & & Hospitalizations & 0 & 4 & \\
\hline & & & & ER visits & 0 & 2 & \\
\hline \multicolumn{8}{|c|}{$\begin{array}{l}\text { aBaseline during } 6 \text { months pre-index period. } \\
\text { bChi-square tests were performed for categorical variables, and independent t-test was performed for continuous variables. } \\
\text { cCounted CVD-related medication prescribed only once, regardless of number of refills. } \\
{ }^{d} \text { This study examined all-cause or total medical claims. All other relevant medical claims were also counted, regardless of whether the claim had a CVD-related ICD-9- } \\
C M \text { diagnosis code. } \\
C V D=\text { cardiovascular disease; ER=emergency room; ICD-9-CM = International Classification of Diseases, Ninth Revision, Clinical Modification; MTM =medication } \\
\text { therapy management; SD=standard deviation. }\end{array}$} \\
\hline
\end{tabular}

per patient attributable to MTM services was calculated by subtracting the average cost of MTM services per patient from the average total benefit per patient (i.e., $\$ 359.3-\$ 134.6=\$ 224.7$ ). This average net benefit per patient was divided by the average cost of MTM services per patient, resulting in an ROI of $\$ 1.67$ per $\$ 1$ in MTM costs per patient in a 6-month period.

\section{Clinical Outcomes}

Table 3 summarizes changes in values of clinical parameters for patients remaining in the clinical cohort. Of the 63 patients in the MTM group, only a portion of them were included in the clinical cohort due to a lack of clinical measurements obtained before and after the index date. Specifically, 40 patients were included in BP analysis, and 23 patients were included in BMI analysis. Since the lipid panel analysis had a relatively small sample size, only descriptive analyses were conducted.

The mean systolic and diastolic BP values at endpoints decreased from the baseline values (Table 3). However, the magnitude of the changes was small, and the mean systolic and diastolic BPs at endpoint were not statistically different from the baseline. In addition to the mean differences, we examined the change in the proportion of patients who achieved their BP treatment goals. The percentage of patients at their goals increased from 55\% at baseline to $70 \%$ at endpoint (6-month pre- and post-index date, respectively). Looking at the distribution of patients by stages of hypertension between 


\section{Evaluation of Medication Therapy Management Services for Patients with Cardiovascular Disease in a Self-Insured Employer Health Plan}

\section{TABLE 2 Per Patient Mean Direct Cost of CVD-Related Expenditures for 6 months Pre- and Post-index Date Among MTM and Non-MTM Groups Enrolled in a Medical and Pharmacy Claims Database: 2008-2010}

\begin{tabular}{|c|c|c|c|c|c|c|c|}
\hline \multirow[b]{3}{*}{ Cost Category } & \multicolumn{3}{|c|}{ MTM Group $(n=63)$} & \multicolumn{3}{|c|}{ Non-MTM Group $(n=62)$} & \multirow[b]{3}{*}{$\begin{array}{l}\text { Between Groups } \\
\text { Cost Difference }\end{array}$} \\
\hline & \multicolumn{2}{|c|}{ Mean Cost [SD] } & \multirow[b]{2}{*}{$\begin{array}{c}\text { Within Group } \\
\text { Cost Difference } \mathrm{a}, \mathrm{c}\end{array}$} & \multicolumn{2}{|c|}{ Mean Cost [SD] } & \multirow[b]{2}{*}{$\begin{array}{l}\text { Within Group } \\
\text { Cost Difference }\end{array}$} & \\
\hline & $\begin{array}{c}6 \text { months } \\
\text { Pre-index Date }\end{array}$ & $\begin{array}{c}6 \text { months } \\
\text { Post-index Date }\end{array}$ & & $\begin{array}{c}6 \text { months } \\
\text { Pre-index Date }\end{array}$ & $\begin{array}{c}6 \text { months } \\
\text { Post-index Date }\end{array}$ & & \\
\hline Pharmacy expenditure & $126.8 \quad[20.3]$ & $104.8 \quad[17.8]$ & $-22.0 \quad[19.1]$ & $133.7 \quad[23.8]$ & $144.4 \quad[24.6]$ & $10.7 \quad[24.2]$ & $-31.9 \quad[25.1]$ \\
\hline Medical expenditure & $235.8[108.8]$ & $156.6 \quad[89.4]$ & [99.6] & {$[48.9]$} & $394.7 \quad[347.9]$ & $246.4 \quad[248.4]$ & $-325.6[271.2]$ \\
\hline Total expenditures & $481.2[137.0]$ & $406.1[135.3]$ & $-75.1 \quad[136.2]$ & $291.3 \quad[49.0]$ & $580.3[309.9]$ & $289.0[269.5]$ & $-359.3[219.2]$ \\
\hline \multicolumn{8}{|c|}{ 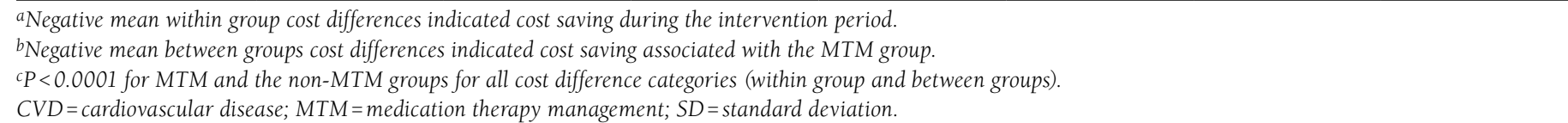 } \\
\hline
\end{tabular}

\section{TABLE 3 Comparison of Lipid Panel, Blood} Pressure, and Body Mass Index between Baseline and Endpoint Values of the MTM Group

\begin{tabular}{|c|c|c|c|c|}
\hline Outcome Par: & $\begin{array}{c}\text { Baseline } \\
\text { Value }^{\mathrm{a}} \\
\text { Mean [SD] }\end{array}$ & $\begin{array}{l}\text { Endpoint } \\
\text { Value }^{\mathrm{a}} \\
\text { Mean [SD] }\end{array}$ & $\begin{array}{c}\text { Mean } \\
\text { Differences } \\
\text { Mean [SD] }\end{array}$ & $\begin{array}{c}P \\
\text { Value }\end{array}$ \\
\hline \multicolumn{5}{|l|}{ Lipid panel $(\mathrm{mg} / \mathrm{dL})^{\mathrm{b}}$} \\
\hline Total & 53.2 [33.9] & [27.7] & $3.8[24.7]$ & N/A \\
\hline & $42.3 \quad[16.5]$ & 44.5 [16.8] & $2.2 \quad[7.4]$ & N/A \\
\hline & $9.3[41$. & 83.5 [19.1] & $-5.8[38.7]$ & N/A \\
\hline Triglyceride & $171.4[111.3]$ & $151.3[70.6]$ & $-20.1[119.9]$ & N/A \\
\hline \multicolumn{5}{|c|}{$(\mathrm{mmHg}), \mathrm{n}=40^{\mathrm{c}}$} \\
\hline & 132.9 [19.0] & $129.6[15.9]$ & [17.5] & 0.160 \\
\hline & [8.6] & $78.9 \quad[7.2]$ & {$[8.4]$} & 0.23 \\
\hline & [6.9] & {$[6.6]$} & {$[1.2]$} & 0.100 \\
\hline \multicolumn{5}{|c|}{$\begin{array}{l}\text { a Baseline value represents value } 6 \text { months before the index date, and endpoint } \\
\text { value represents value } 6 \text { months after the index date. } \\
\text { bStatistical tests cannot be performed due to small sample size. } \\
\text { 'Results were not significantly different from baseline }(P \geq 0.05) \text {, using paired t-test. } \\
\text { HDL=high-density lipoprotein; } \mathrm{kg} / \mathrm{m}^{2}=\text { kilogram per square meter; } \mathrm{LDL}=\text { low- } \\
\text { density lipoprotein; } \mathrm{mg} / \mathrm{dL}=\text { milligram per deciliter; } \mathrm{mmHg}=\text { millimeter of mercury; } \\
\text { MTM= medication therapy management; } N A=\text { not applicable; } S D=\text { standard deviation. }\end{array}$} \\
\hline
\end{tabular}

the baseline values and the endpoint values (Table 4), improvements in the hypertension stage were observed in the post-index period $\left(\chi^{2}=12.77, P=0.01\right)$. For instance, of 16 patients that had pre-hypertension at baseline, 13 (81.3\%) remained at their current stages while $3(18.8 \%)$ had improved to the normal stage post-index date. Further, half of patients with stage 1 hypertension at baseline had improved at least 1 stage. Specifically, 1 patient had improved to the normal stage, and 7 patients had improved to the pre-hypertension stage.

Parallel to the BP analyses, body BMI values at baseline and endpoint were compared (Table 3). The BMI value at endpoint decreased from the baseline value. However, the magnitude of the change was small, and no statistically significant differences were detected. In addition to the mean differences, the study examined the change in the proportion of patients who achieved a normal BMI. The percentage of patients at a BMI goal increased from $13 \%$ at baseline to $22 \%$ at endpoint. Looking at BMI categories (Table 5), similar improvements were noted $\left(\chi^{2}=6.39, P<0.05\right)$. For instance, of the 11 patients that were classified as overweight at baseline, $9(81.8 \%)$ remained overweight, while 2 (18.2\%) had improved to a normal category at the post-index date. Similarly, 3 patients (33.3\%) who were classified as obese at baseline had improved one stage to the overweight category at the post-index date.

\section{Discussion}

The primary purpose of this study was to evaluate the impact of MTM services among patients with CVD from the selfinsured employer perspective. The results of this study were consistent with previous studies in which comprehensive MTM services were provided, indicating improvements in economic and clinical outcomes in the MTM group.

The economic analyses of this study can be compared with a few other studies of MTM services that have used a pre- and post-design with a comparison group. ${ }^{32,35,48,49}$ In an attempt to minimize selection bias, we used a matched pairs analysis that selected comparison patients based on similarity to MTM patients with regard to age, disease states, and CCI scores. Our matched sample was similar in most regards to the MTM group. Further, patients in our study had similar characteristics to that of patients with CVD reported in prior studies. ${ }^{13,29}$ Additionally, while this study had a relatively small sample size, it should be recognized that a small sample size $(\mathrm{n}<100)$ is quite common, especially among studies that have evaluated real-world clinical outcomes. . $^{29,31,48,50}$

From an economic perspective, the decrease in CVD-related pharmacy, all-cause medical costs, and total expenditures 


\section{Evaluation of Medication Therapy Management Services for Patients with Cardiovascular Disease in a Self-Insured Employer Health Plan}

TABLE 4 Cross-Tabulation of Patients by Stages of Hypertension Between Baseline and Endpoint

\begin{tabular}{|c|c|c|c|c|c|c|c|}
\hline \multirow[b]{2}{*}{$\begin{array}{l}\text { Stages of BP at Baseline } \\
\text { (SBP/DBP, } \mathrm{mmHg} \text { ) }\end{array}$} & \multirow[b]{2}{*}{$\begin{array}{l}\text { Baseline }^{\mathrm{a}} \\
\text { n (\%) }\end{array}$} & \multicolumn{5}{|c|}{ Endpoint $^{\mathrm{a}}$} & \multirow[b]{2}{*}{$\begin{array}{l}P \text { Value }^{\mathrm{b}} \\
\left(\chi^{2}\right)\end{array}$} \\
\hline & & $\begin{array}{c}\text { Normal } \\
\text { n (\%) }\end{array}$ & $\begin{array}{l}\text { Pre-HTN } \\
\text { n (\%) }\end{array}$ & $\begin{array}{c}\text { Stage } 1 \text { HTN } \\
\text { n (\%) }\end{array}$ & $\begin{array}{c}\text { Stage } 2 \text { HTN } \\
\text { n (\%) }\end{array}$ & $\begin{array}{c}\text { Changes } \\
(\%)\end{array}$ & \\
\hline Normal $(<120 / 80)$ & $(12.5)$ & 3 & 2 & & & 40.0 & \multirow{4}{*}{12.77} \\
\hline Pre-HTN (120-139/80-89) & $16 \quad(40.0)$ & 3 & 13 & & & 43.8 & \\
\hline Stage 1 HTN (140-159/90-99) & $16 \quad(40.0)$ & 1 & 7 & 7 & 1 & -56.3 & \\
\hline Stage 2 HTN $(\geq 160 / \geq 100)$ & $3 \quad(7.5)$ & 0 & 1 & 0 & 2 & 0.0 & \\
\hline Total & $40 \quad(100.0)$ & $7(18.0)$ & $23(58.0)$ & $7(18.0)$ & $3(8.0)$ & & \\
\hline
\end{tabular}

\section{TABLE 5 Cross-Tabulation of Patients by Stages of Body Mass Index Between Baseline and Endpoint}

\begin{tabular}{|c|c|c|c|c|c|c|c|c|}
\hline \multirow[b]{2}{*}{$\begin{array}{l}\text { Stages of Body Mass Index } \\
\left(\mathrm{kg} / \mathrm{m}^{2}\right)\end{array}$} & \multirow{2}{*}{\multicolumn{2}{|c|}{$\begin{array}{l}\text { Baseline }^{\mathrm{a}} \\
\text { n (\%) }\end{array}$}} & \multicolumn{4}{|c|}{ Endpoint $^{\mathrm{a}}$} & \multirow[b]{2}{*}{$\begin{array}{c}\text { Changes } \\
(\%)\end{array}$} & \multirow[b]{2}{*}{$\begin{array}{l}P \text { Value }^{\mathrm{b}} \\
\left(\chi^{2}\right)\end{array}$} \\
\hline & & & $\begin{array}{c}\text { Underweight } \\
\text { n (\%) }\end{array}$ & $\begin{array}{l}\text { Healthy } \\
\text { n (\%) }\end{array}$ & $\begin{array}{c}\text { Overweight } \\
\text { n (\%) }\end{array}$ & $\begin{array}{l}\text { Obese } \\
\mathrm{n}(\%)\end{array}$ & & \\
\hline Underweight $(<18.5)$ & 0 & $(0.0)$ & & & & & 0.0 & \multirow{4}{*}{6.39} \\
\hline Healthy (18.5-24.9) & 3 & $(13.0)$ & & 3 & & & 66.7 & \\
\hline Overweight (25.0-29.9) & 11 & $(47.8)$ & & 2 & 9 & & 9.1 & \\
\hline Obese $(\geq 30.0)$ & 9 & $(39.1)$ & & & 3 & 6 & -33.3 & \\
\hline Total & 23 & $(100.0)$ & 0 & $5(22.0)$ & $12(52.0)$ & $6(26.0)$ & & \\
\hline
\end{tabular}

a Baseline value represents value 6 months before the index date, and endpoint value represents value 6 months after the index date.

bStatistically significant difference at $P<0.05$, using generalization of the McNemar's chi-square (Bhapkar's) test for the marginal homogeneity testing. $\mathrm{kg} / \mathrm{m}^{2}=$ kilogram per square meter.

found in this study was similar to previous studies regarding pharmacist-provided MTM services, including the Asheville Project and the Minnesota experience..$^{10,11}$ The decline in aggregate cost of total expenditures between 6-month pre- and post-index dates in the MTM group suggests that patients may have received a patient-specific pharmacotherapy assessment provided during MTM encounters, resulting in lower expenditures after the index date. In contrast, medical expenditures of the non-MTM group increased by $63.7 \%$ or twice as much as the MTM group, resulting in an increase of $47.2 \%$ of total expenditures 6 months after the index date. Given our small sample size and the slightly higher use of ER visits and hospitalizations in the baseline period for the comparator group, our results could be biased. For example, while significant and positive, the increase in all expenditures in the non-MTM group 6 months after the index date could be a result of worsening medical condition during the study period. However, it is important to note that both groups were similar in terms of comorbidity at baseline, and reasonable attempts were made to minimize gross differences.

In terms of cost savings, the study demonstrates the impact of pharmacist-provided MTM services on positive direct cost savings ( $\$ 359.3$ per person) in a 6 -month period. This finding is similar to previous studies where direct cost savings per patient ranged from $\$ 71.21$ to $\$ 290.60 .^{12,31,35,51}$ The positive ROI of 1.67 in a 6 -month period suggests that MTM services offered a positive financial benefit for the self-insured employer. The findings from this study were consistent with previous studies that reported ROIs between 1.49-12.15. ${ }^{10-12,52}$ Therefore, similar to prior studies, pharmacist-led MTM services are worthwhile to be incorporated as part of the health insurance benefit package.

In terms of clinical outcomes, several things should be highlighted. First, this is the first identifiable study that evaluated the effect of MTM services on BMI, which is a major risk factor of CVD. ${ }^{1}$ Second, the population in the current study was similar to the CVD populations of previous studies. In this study, 55\% of participants in the MTM group had their BP controlled at baseline, which was consistent with the Minnesota experience study and the Asheville Project. ${ }^{10,11}$ Additionally, the percentage of patients who were classified as overweight or obese was approximately $87 \%$ at baseline, which was consistent with a previous study conducted by Planas et al. (2009). ${ }^{29}$ Third, although the differences between baseline and endpoint values of BP and BMI in this study were not statistically significant, the magnitude of differences appeared to be clinically 


\section{Evaluation of Medication Therapy Management Services for Patients with Cardiovascular Disease in a Self-Insured Employer Health Plan}

significant in terms of achieving individualized goals and changes in disease stages. With respect to BP, this study is comparable with the results found in the Asheville Project, which reported improvement in percentages of patients with $\mathrm{BP}$ readings in hypertension stages I and II. ${ }^{10}$

The findings of this study support the value of pharmacist-provided MTM services as proposed by the American Pharmacist Association, which states that MTM services help improve therapeutic outcomes and reduce health care costs. ${ }^{53}$ This study provides support for these services from the perspective of self-insured employers. The findings from this study can inform self-insured employers of the value and benefits of pharmacist-provided MTM services. Payers may use this information to justify why pharmacist-provided MTM services should be included in their health care benefits to their beneficiaries as a way to address rising cost concerns, especially among patients with CVD. Also, this study may provide a framework for optimizing patient therapeutic outcomes while ensuring cost savings for policy and decision makers.

\section{Limitations}

A number of limitations in this study should be noted. First, due to the nonrandomized nature of this study, patients' selfselection to participate in the MTM program could increase the potential of selection bias. That is, patients who were more proactive and engaged in their own health might tend to obtain MTM services compared with those in the non-MTM group. Also, physicians may have induced a selection bias because they may have encouraged patients who had complex drug regimens to receive MTM services from the PCC. This selection bias may affect the results in a favorable way for the MTM group. To minimize the potential selection bias, a matched-pair method was used to select patients into a comparison group that had similar characteristics. Next, while unlikely, it is also possible that participants in the non-MTM group received MTM services elsewhere, and their visits were cash-based and not reflected in the claims. The accuracy of pharmacy and medical expenditures used in the analysis depend on how claims and codes were billed for each patient. Another limitation was related to the lack of data when physicians dispensed drug samples to patients in their offices. The use of drug samples may affect pharmacy expenditures because patients received drug samples to help decrease their financial burden instead of filling their prescriptions. Further, we were unable to track those patients who bought their medications over the counter, and this limitation might underestimate pharmacy expenditures. Our study had a relatively small sample size for both MTM and non-MTM groups. Small sample size may reduce the power to detect statistically significant differences or could allow for spurious findings. Further, missing clinical data further reduced sample size for these analyses.
For the clinical analysis, clinical data were retrieved from an EMR database, and paper records were not available to supplement missing clinical parameters. Attempts were made to retrieve patient information from supplemental documents that had been scanned and attached to the patient profile, but these forms could not be systematically used. Also, an adjustment for baseline covariates such as demographic variables (e.g., age and CCI score) and adherence rates were not included in the clinical analysis. These variables may have an influence on clinical outcomes, and without a comparison group, our findings may be biased. Moreover, the effect of MTM services alone is difficult to measure because the effect of medications could impact patients' clinical outcomes. Further, MTM services offered to patients in the MTM group may not have been consistent with all pharmacists at the PCC. For instance, some pharmacists might detect more DRPs than others, which may result in better outcomes among their patients as compared with patients whose problems were not detected. Lastly, the white coat effect was possible when measuring patients' BP.

This study may have limited generalizability. First, the study population was employees and their dependents who enrolled in a university-based insurance plan, and these patients and the environment may not be generalizable to other populations. Second, differences between MTM services offered by the PCC and other pharmacist-provided MTM services, as well as beneficiaries' accessibility to the PCC, may limit the generalizability of the results to other settings. Because the PCC clinic is located onsite, it is convenient for employees to access the service. Therefore, generalizing the study findings to other settings where accessibility to the service is an issue may be limited. Finally, the findings of this study were based on a face-to-face MTM service personally delivered by pharmacists. It may not be generalized to MTM services for CVD with different delivery methods, such as telephonic interaction, mail intervention, interactive video, or other qualified health care practitioners, such as nurses.

\section{Conclusions}

Our study provides evidence that MTM services statistically reduced CVD-related pharmacy and all-cause medical expenditures among participants in the MTM group as compared with the non-MTM group, and the ROI in a 6-month period indicated the positive value of MTM services. Further, while changes in clinical outcomes were not statistically significant, MTM services demonstrated promising clinical benefits in terms of achieving goals and improving disease stages. This is the first known study to document improvements in BMI for patients receiving pharmacist-provided MTM services. Finally, this study supports the role of pharmacists in identifying and addressing DRPs, which leads to better economic and clinical outcomes for patients with CVD. 


\section{Evaluation of Medication Therapy Management Services for Patients with Cardiovascular Disease in a Self-Insured Employer Health Plan}

\section{Authors}

SARANRAT WITTAYANUKORN, BSc, MS, is a PhD student; SALISA C. WESTRICK, PhD, is Associate Professor; RICHARD A. HANSEN, PhD, is Professor and Department Head; BRENT I. FOX, PharmD, PhD, is Associate Professor; and KIMBERLY B. GARZA, PharmD, MBA, PhD, is Assistant Professor, Department of Pharmacy Care Systems; and KIMBERLY BRAXTON-LLOYD, PharmD, is Associate Professor of Pharmacy Practice and Assistant Dean of Health Service, Auburn University Harrison School of Pharmacy, Auburn, Alabama. NEDRET BILLOR, PhD, is Associate Professor of Mathematics and Statistics, Department of Mathematics and Statistics, Auburn University, Auburn, Alabama.

AUTHOR CORRESPONDENCE: Saranrat Wittayanukorn, BSc, MS, Department of Pharmacy Care Systems, Auburn University Harrison School of Pharmacy, 020 James E Foy Hall, Auburn, AL 36849-5506. Tel.: 334.844.5152; Fax: 334.844.8307; Email:szw0022@tigermail.auburn.edu.

\section{DISCLOSURES}

No outside funding supported this research project. A poster abstract of this manuscript was presented at the annual meeting of the American Pharmacists Association, March 9-12, 2012, New Orleans, Louisiana.

Concept and design were performed by Wittayanukorn, Westrick, and Hansen, with help from Billor, Fox, and Garza. Data were collected by Wittayanukorn, Braxton-Lloyd, and Westrick, with help from Hansen, Billor, and Garza. Data were interpreted by Hansen, Billor, Wittayanukorn, Westrick, and Braxton-Lloyd, with help from Fox and Garza. Wittayanukorn wrote the manuscript with help from Westrick, Hansen, and Billor. The manuscript was revised by Fox, Garza, Braxton-Lloyd, Wittayanukorn, Westrick, and Billor, with help from Hansen.

\section{ACKNOWLEDGEMENT}

The authors would like to extend their appreciation to Dr. David Brackett for his guidance in data collection from the electronic medical record.

\section{REFERENCES}

1. Roger VL, Go AS, Lloyd-Jones DM, et al. Heart disease and stroke statistics-2012 update: a report from the American Heart Association. Circulation. 2012;125(1):e2-e220.

2. Roger VL, Go AS, Lloyd-Jones DM, et al. Heart disease and stroke statistics-2011 update: a report from the American Heart Association. Circulation. 2011;123(4):e18-e209.

3. Xu J, Kochanek KD, Murphy SL, et al. Deaths: final data for 2007. Natl Vital Stat Rep. 2010;58(19):1-135.

4. Agency for Healthcare Research and Quality. Total expenses and percent distribution for selected conditions by type of service: United States, 2008. Medical Expenditure Panel Survey Household Component Data. Generated interactively. (April 27, 2013). Available at: http://www.meps. ahrq.gov/mepsweb/data_stats/tables_compendia_hh_interactive.jsp? SERVICE $=$ MEPSSocket0\&_PROGRAM=MEPSPGM.TC. SAS\&File=HCFY200 8\&Table=HCFY2008\%5FCNDXP\%5FC\&_Debug=. Accessed April 27, 2013.

5. Facts and figures 2008 - highlights. Healthcare Cost and Utilization Project (HCUP). October 2010. Agency for Healthcare Research and Quality, Rockville, MD. Available at: http://www.hcup-us.ahrq.gov/reports/factsandfigures/2008/highlights.jsp. Accessed April 27, 2013.
6. Heidenreich PA, Trogdon JG, Khavjou OA, et al. Forecasting the future of cardiovascular disease in the United States: a policy statement from the American Heart Association. Circulation. 2011;123(8):933-44.

7. Government Finance Officers Association. Best practice. Strategic healthcare plan design (2009) (CORBA). 2009. Available at: http://www.gfoa.org/ index.php?option=com_content\&task=view\&id=1626. Accessed April 27, 2013.

8. Joyce GF, Escarce JJ, Solomon MD, et al. Employer drug benefit plans and spending on prescription drugs. JAMA. 2002;288(14):1733-39.

9. National Center for Health Statistics. Health, United States, 2010: with special feature on death and dying. Hyattsville, MD. 2011. Available at: http://www.cdc.gov/nchs/data/hus/hus10.pdf\#121. Accessed April 27, 2013.

10. Bunting BA, Smith BH, Sutherland SE. The Asheville Project: clinical and economic outcomes of a community-based long-term medication therapy management program for hypertension and dyslipidemia. J Am Pharm Assoc (2003). 2008;48(1):23-31.

11. Isetts BJ, Schondelmeyer SW, Artz MB, et al. Clinical and economic outcomes of medication therapy management services: the Minnesota experience. J Am Pharm Assoc (2003). 2008;48(2):203-11.

12. Johannigman MJ, Leifheit M, Bellman N, Pierce T, Marriott A, Bishop C. Medication therapy management and condition care services in a community-based employer setting. Am J Health Syst Pharm. 2010;67(16):1362-67.

13. Barnett MJ, Frank J, Wehring H, et al. Analysis of pharmacist-provided medication therapy management (MTM) services in community pharmacies over 7 years. J Manag Care Pharm. 2009;15(1):18-31. Available at: http:// www.amcp.org/WorkArea/DownloadAsset.aspx?id=8064.

14. Klopotowska JE, Kuiper R, van Kan HJ, et al. Onward participation of a hospital pharmacist in a Dutch intensive care unit reduces prescribing errors and related patient harm: an intervention study. Crit Care. 2010;14(5):R174

15. Leape LL, Cullen DJ, Clapp MD, et al. Pharmacist participation on physician rounds and adverse drug events in the intensive care unit. JAMA 1999;282(3):267-70.

16. Kucukarslan SN, Peters M, Mlynarek M, Nafziger DA. Pharmacists on rounding teams reduce preventable adverse drug events in hospital general medicine units. Arch Int Med. 2003;63(17):2014-18

17. Kopp BJ, Mrsan M, Erstad BL, et al. Cost implications of and potential adverse events prevented by interventions of a critical care pharmacist. Am J Health Syst Pharm. 2007;64(23):2483-87.

18. Bero LA, Mays NB, Barjesteh K, et al. Expanding the roles of outpatient pharmacists: effects on health services utilisation, costs, and patient outcomes. Cochrane Database of Syst Rev. 2000;(2):CD000336.

19. Nkansah N, Mostovetsky O, Yu C, et al. Effect of outpatient pharmacists' non-dispensing roles on patient outcomes and prescribing patterns. Cochrane Database of Syst Rev. 2010;(7):CD000336.

20. Chisholm-Burns MA, Graff Zivin JS, Lee JK, et al. Economic effects of pharmacists on health outcomes in the United States: a systematic review. Am J Health Syst Pharm. 2010;67(19):1624-34.

21. Elliott RA, Barber N, Clifford S, Horne R, Hartley E. The cost effectiveness of a telephone-based pharmacy advisory service to improve adherence to newly prescribed medicines. Pharm World Sci. 2008;30(1):17-23.

22. Chisholm-Burns MA, Kim Lee J, Spivey CA, et al. US pharmacists' effect as team members on patient care: systematic review and meta-analyses. Med Care. 2010;48(10):923-33.

23. Machado M, Bajcar J, Guzzo GC, Einarson TR. Sensitivity of patient outcomes to pharmacist interventions. Part I: systematic review and metaanalysis in diabetes management. Ann Pharmacother. 2007;41(10):1569-82.

24. Benavides S, Rodriguez JC, Maniscalco-Feichtl M. Pharmacist involvement in improving asthma outcomes in various healthcare settings: 1997 to present. Ann Pharmacother. 2009;43(1):85-97. 


\section{Evaluation of Medication Therapy Management Services for Patients with Cardiovascular Disease in a Self-Insured Employer Health Plan}

25. Bodenheimer T, Chen E, Bennett HD. Confronting the growing burden of chronic disease: can the U.S. health care workforce do the job? Health Aff (Millwood). 2009;28(1):64-74.

26. Carter BL, Rogers M, Daly J, et al. The potency of team-based care interventions for hypertension: a meta-analysis. Arch Int Med. 2009;169(19):1748-55

27. Sandhoff BG, Nies LK, Olson KL, Nash JD, Rasmussen JR, Merenich JA. Clinical pharmacy cardiac risk service for managing patients with coronary artery disease in a health maintenance organization. Am J Health Syst Pharm. 2007;64(1):77-84

28. Centers for Disease Control and Prevention. Vital signs: health insurance coverage and health care utilization-United States, 2006-2009 and January-March 2010. MMWR Morb Mortal Wkly Rep. 2010;59(44):1448-54 Available at: http://www.cdc.gov/mmwr/preview/mmwrhtml/mm5944a5. htm. Accessed April 27, 2013.

29. Planas LG, Crosby KM, Mitchell KD, et al. Evaluation of a hypertension medication therapy management program in patients with diabetes. J Am Pharm Assoc (2003). 2009;49(2):164-70

30. National Committee for Quality Assurance and Academy of Managed Care Pharmacy. Developing a robust quality measurement approach for Medicare Part D. May 2006. Available at: http://www.ncqa.org/Portals/0/ Publications/Resource\%20Library/White\%20Papers/MedPartD.pdf. Accessed April 27, 2013.

31. Maack B, Miller DR, Johnson T, Dewey M. Economic impact of a pharmacy resident in an assisted living facility-based medication therapy management program. Ann Pharmacother. 2008;42(11):1613-20.

32. Stockl KM, Tjioe D, Gong S, Stroup J, Harada AS, Lew HC. Effect of an intervention to increase statin use in medicare members who qualified for a medication therapy management program. J Manag Care Pharm. 2008;14(6):532-40. Available at: http://www.amcp.org/WorkArea/ DownloadAsset.aspx?id=7944

33. Ramalho de Oliveira D, Brummel AR, Miller DB. Medication therapy management: 10 years of experience in a large integrated health care system. J Manag Care Pharm. 2010;16(3):185-95. Available at: http://www.amcp.org/ WorkArea/DownloadAsset.aspx?id=8313

34. Crimmel BL. Self-insured coverage in employer-sponsored health insurance for the private sctor, 2000 and 2010. Statistical Brief \#339. Agency for Healthcare Research and Quality, Rockville, MD. September 2011. Available at: http://meps.ahrq.gov/mepsweb/data_files/publications/st339/stat339.pdf. Accessed April 27, 2013

35. Pindolia VK, Stebelsky L, Romain TM, Luoma L, Nowak SN, Gillanders F. Mitigation of medication mishaps via medication therapy management. Ann Pharmacother. 2009;43(4):611-20.

36. Hepler CD, Strand LM. Opportunities and responsibilities in pharmaceutical care. Am J Hosp Pharm. 1990;47(3):533-43.

37. Cipolle RJ, Strand LM, Morley PC. Pharmaceutical Care Practice: The Clinician's Guide. 2nd ed. New York: McGraw-Hill; 2004

38. National Cholesterol Education Program (NCEP) Expert Panel on Detection Evaluation and Treatment of High Blood Cholesterol in Adults (Adult Treatment Panel III). Third report of the National Cholesterol Education Program (NCEP) Expert Panel on Detection, Evaluation, and Treatment of High Blood Cholesterol in Adults (Adult Treatment Panel III) final report. Circulation. 2002;106(25):3143-421.
39. Streiner DL. The case of the missing data: methods of dealing with dropouts and other research vagaries. Can J Psychiatry. 2002;47(1):68-75.

40. Charlson ME, Pompei P, Ales KL, MacKenzie CR. A new method of classifying prognostic comorbidity in longitudinal studies: development and validation. J Chronic Dis. 1987;40(5):373-83.

41. Solomon DH, Glynn RJ, Levin R, Avorn J. Nonsteroidal antiinflammatory drug use and acute myocardial infarction. Arch Int Med. 2002;162(10):1099-104

42. O'Sullivan AK, Rubin J, Nyambose J, Kuznik A, Cohen DJ, Thompson D. Cost estimation of cardiovascular disease events in the US. Pharmacoeconomics. 2011;29(8):693-704.

43. Briggs AH, Wonderling DE, Mooney CZ. Pulling cost-effectiveness analysis up by its bootstraps: a non-parametric approach to confidence interval estimation. Health Econ. 1997;6(4):327-40.

44. Rascati KL, Smith MJ, Neilands T. Dealing with skewed data: an example using asthma-related costs of medicaid clients. Clin Ther. 2001;23(3):481-98.

45. Efron B, Tibshirani R. An Introduction to the Bootstrap. New York: Chapman and Hall; 1994.

46. Fiellin DA, Feinstein AR. Bootstraps and jackknives: new, computerintensive statistical tools that require no mathematical theories. J Investig Med. 1998:46(2):22-26

47. Committee for Medicinal Products for Human Use (CHMP). Guideline for clinical trials in small populations. European Medicines Agency. July 27, 2006. Available at: http://www.ema.europa.eu/docs/en_GB/document_library/ Scientific_guideline/2009/09/WC500003615.pdf. Accessed April 27, 2013.

48. Christensen DB, Roth M, Trygstad T, et al. Evaluation of a pilot medication therapy management project within the North Carolina State Health Plan. J Am Pharm Assoc (2003). 2007;47(4):471-83.

49. Hirsch JD, Rosenquist A, Best BM, Miller TA, Gilmer TP. Evaluation of the first year of a pilot program in community pharmacy: HIV/AIDS medication therapy management for Medi-Cal beneficiaries. J Manag Care Pharm. 2009;15(1):32-41. Available at: http://www.amcp.org/WorkArea/ DownloadAsset.aspx?id=8066.

50. Chrischilles EA, Carter BL, Lund BC, et al. Evaluation of the Iowa Medicaid pharmaceutical case management program. J Am Pharm Assoc (2003). 2004:44(3):337-49

51. Cote I, Gregoire JP, Moisan J, et al. A pharmacy-based health promotion programme in hypertension: cost-benefit analysis. Pharmacoeconomics. 2003;21(6):415-28.

52. U.S. Department of Health and Human Services. Prevention makes common "cents": executive smmary. Washington, DC: U.S. Department of Health and Human Services. 2003. Available at: http://aspe.hhs.gov/health/ prevention/prevention.pdf. Accessed April 27, 2013.

53. American Pharmacists Association. Understanding Medicare Reform: What Pharmacists Need to Know. Monograph 2: Medication Therapy Management Services and Chronic Care Improvement Programs. Washington, DC: American Pharmacists Association; 2004. 
Evaluation of Medication Therapy Management Services for Patients

with Cardiovascular Disease in a Self-Insured Employer Health Plan

\begin{tabular}{l|l}
\hline \multicolumn{1}{c}{ APPENDIX } & $\begin{array}{l}\text { ICD-9-CM Diagnosis Codes Used to } \\
\text { Identify CVD in Medical Claims }\end{array}$ \\
\hline Code & \multicolumn{1}{c}{ Description } \\
\hline 72 & Hyperlipidemia \\
\hline $01-405$ & Hypertension \\
\hline $10-414$ & Coronary heart disease \\
\hline $15-417$ & Disease of pulmonary circulation \\
\hline $20-429$ & Other form of heart disease \\
\hline $30-438$ & Heart failure \\
\hline $40-448$ & Cerebrovascular disease (stroke) \\
\hline $451-459$ & Disease of arteries, arterioles, and capillaries \\
\hline CVD 747 & Disease of veins and lymphatics and other diseases \\
Diseases, Ninth Revision, Clinical Modification.
\end{tabular}

